\title{
Diversity and Taxonomical Identification of Rays in Pondicherry (Puducherry) Coastal Waters
}

\author{
Nithya Mary Srinivasan*1, Ravitchandirane Vaithilingam ${ }^{2}$ and Gunalan Balakrishnan ${ }^{2}$ \\ ${ }^{1}$ Department of Zoology, Pondicherry University, India \\ ${ }^{2}$ Department of Zoology, Thiruvalluvar University, India \\ Submission: May 01, 2021; Published: July 06, 2021 \\ Corresponding author: Nithya Mary S, Department of Zoology, Kanchi Mamunivar Government Institute of Post Graduate Studies and Research, \\ Pondicherry University, Puducherry, India
}

\begin{abstract}
India is one of the leading elasmobranch-fishing countries, with catch data exhibiting a continuous decline in landing over the last two decades. Elasmobranch research is limited in India despite its rich diversity, long history, and huge fishery. The present study was carried out for a period of 18 months from November 2019 to April 2021 in four landing centres of Pondicherry coastal waters. Totally seven rays were recorded, belongs two order and four families. Due lack of data on diversity of rays and taxonomy, the present research work was carried out.
\end{abstract}

Keywords: Rays; Pillaichavadi; Periyakalapet; Veerampattinam; Nallavadu; Pondicherry coast; Taxonomy; Diversity

\section{Introduction}

Elasmobranchs indicate (shark, sawfishes, rays, and skates) some of the most endangered marine species across the world [1]. They are slow growing and yield relatively few young, which makes them very vulnerable to human activities such as fishing; masses of sharks and rays are caught by fishing vessels every year. India is among the top three elasmobranch fishing countries, and these species contribute to source of revenue and food security of thousands in the country. However, catches in the country have been declining over the past few decades, indicating that elasmobranch populations are under serious threat [2]. The Elasmobranchs contributed approximately $4 \%$ of the India and $3 \%$ of the Tamil Nadu catches [3]. Among the total elasmobranchs catches, $1.6 \%$ (823.6 t) of the catches was from Kasimedu, Chennai, and Tamil Nadu. Catch using trawl nets was highly dominated by sting rays (74.1\%), whereas Carcharhinid sharks (51.1\%) were dominant in the catch by mechanized gillnet.

The elasmobranchs fishery in Chennai constituted 13 species of sharks, 13 species of rays, and 4 species of guitar fishes [4]. Documenting chondrichthyans (Elasmobranchs) regions and understanding their taxonomy and diversity in specific ecosystems are very important for safeguarding and management of these decreasing resources. Elasmobranchs research is limited in India even though it is rich diversity, long history, and huge fishery. Especially in Pondicherry coastal waters there is no proper documentation of elasmobranchs. Due to very less work and fulfilling the lack of study on diversity of elasmobranch special reference with diversity and taxonomical characters of ray fishery were carried out.

\section{Material and Methods}

Puducherry region is situated on the coromandel cast between $11^{\circ} 45^{\prime}$ and $12^{\circ} 03^{\prime} \mathrm{N}$ latitudes and $79^{\circ} 37^{\prime}$ and $79^{\circ} 53^{\prime} \mathrm{E}$ longitudes with an area of $293 \mathrm{~km}^{2}$ and the coastal shoreline area assessed 24 $\mathrm{km}$. The present study was carried out for a period of 18 months from November 2019 to April 2021 in four landing centres (Periyakalapet (12²' 13": 79 51' 58" NW9194), Pillaichavadi

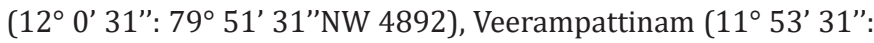

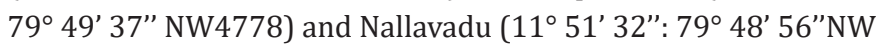
3543)) to study the ray fish diversity in Puducherry coastal waters. Samples were collected and observed every three days once all landing centres. Rays were identified using FAO sheets and CMFRI special publication.

\section{Results}

In the present study totally 7 species were recorded from four landing centre of Pondicherry coastal waters. Three species belongs to Dasyatidae family, two species belong to Narcinidae family, one species belongs to Narkidae family, and one species 
belongs to Torpedinidae family. Species recorded in order Torpediniformes are Narcine prodorsalis, Narcine timeli, Narke dipterygia and Torpedo panther. Brevitrygon imbricate, Pateobatis jenkinsii, Neotrygon kuhlii were belongs to order Myliobatiformes. Brevitrygon imbricate and Narcine timeli recorded in all landing centre. Narke dipterygia and Neotrygon kuhlii recorded in Pillaichavadi landing centre. Pateobatis jenkinsii, Torpedo panthera and Narcine prodorsalis recorded in Nallavadu landing centre.

\section{Taxonomical identification characters}

\section{Brevitrygon imbricate}

The scaly whipray (Brevitrygon imbricata) is a species of stingray in the order Myliobatiformes and family Dasyatidae. Disc width equal to disc length; tail shorter than body; ventral surface of disc entirely white. Small whipray with sub-oval disc, pointed snout, disc slightly longer than width. Cross-shaped band of denticles on disc, no large sized dorsal denticles. Moderately elongate tail, with a row of spear shaped thorns (up to 6); tail base depressed with 1 or 2 spines. Apex of pectoral broadly rounded. Dorsal surface pale brown to yellowish brown, margins pale, ventral side white.

\section{Pateobatis jenkinsii}

Large sized whipray with broad rhomboid disc, with a short, broad snout, band of flat denticles on central disc (poorly developed in young); granular patch on upper surface of disc and row of heart shaped dermal denticles from below the spiracle extending on to tail. Pectoral fin with rounded outer margin, pelvic fin small and narrow. Cylindrical and depressed tail with no fin folds; tail with row of upright thorns; tail shorter than length of disc. Dorsal surface uniformly yellowish brown (rarely with small dark spots on disc near tail base), black beyond tail sting, ventral white. IUCN Red List status : Vulnerable.

\section{Narke dipterygia}

Small ray with a sub circular disc with a very short snout; body entirely naked above and below, without dermal denticles or thorns. Mouth very small and not strongly arched. Eyes very small, partly/sometimes embedded in skin, spiracles larger than eye. Nostrils slit-like. Single dorsal fin originating over pelvic free rear tips. Pelvic fins broad. Dorsal surface plain to reddish brown with white bars/blotches on sides of tail extending anteriorly to above rear pelvic fin bases; and on rear of pectoral disc; ventral surface white.

\section{Neotrygon kuhlii}

Small stingray with a smooth rhomboidal disc with somewhat angular apices; anterior margin almost straight; snout broadly rounded; tip seldom pointed. Eyes large and protruding. Denticles confined to single row of short, thorn-like structures along disc midline; cutaneous tail folds prominent, fold located beyond sting. Tail relatively broad-based, slightly depressed, slender, and compressed beyond sting; banded beyond sting. Dorsal surface greyish/greenish, or brownish with prominent bluish spots or bluish-white dark-edged ocelli; spots and ocelli variable in size and number; ventral surface mostly pale.

\section{Narcine timlei}

Disc soft, oval or Sub trapezoidal, widest near mid-length; eyes usually smaller than spiracles; eyes and spiracles joined together; spiracles rounded, with elevated smooth rims; $1^{\text {st }}$ dorsal fin originating slightly posterior to pelvic fin insertion; mouth width slightly wider than internarial space; tooth bands sub equal about half of mouth width. Colour: Dorsally uniform yellowish, brownish, or purplish brown; posterior margins of dorsal fins, lateral tail region and posterior pelvic borders whitish; ventrally creamy white.

\section{Torpedo panthera}

Medium sized torpedo with small clusters of isolated, and sometimes blurry whitish spots over the disc, pelvic fins, and tail. Disc fleshy and broadly circular. Margin of spiracles with 7 short tentacles or papillae. Inter dorsal distance roughly equal to the distance between the 2 nd dorsal and caudal fin. The body colour pale to reddish brown with white markings.

\section{Narcine prodorsalis}

The Narcine prodorsalis is medium size animals characterized by having numerous small regular dark black and brown spots and the background is light brown and an oval to heart shaped disc. The species may resemble with Chinese numbfish and small spot numbfish but relatively distinguishable by the colour pattern and smaller spots [5] (Table 1) (Figures 1-9).

\section{Discussion}

Diversity of rays on the south coast of India is denoted by 65 valid ray species $[6,7]$. India is one of the leading elasmobranchfishing countries [5], with catch data showing a continuous decline in landing over the last two decades [8]. When trawl fishing is well-known for its lack of selectivity [9], a significant portion of rays was captured from trawl nets, gill nets and long lines [10]. Bengal whipray (Brevitrygon imbricate) is a common commercial ray fish in the south coast, especially in Tamil Nadu. They are rarely documented as discards in Muttom and Colachel harbours. The species is scattered in the Indo-west Pacific. They are demersal fishes occupying at depth up to $55 \mathrm{~m}$. feeding of the ray fish is not well known [5]. It predominantly feeds on benthic invertebrates [11]. In the present study also Brevitrygon imbricate recorded in all landing centre.

The Brown numb fish, Narcine timlei was recorded from the southwest coast of Kerala and Tamil Nadu. The species showed less abundance in the trawl bycatch. This species is dispersed in the Indo-west Pacific region. They are benthic and more numbers in shallow waters. Little is known about the biology and fecundity ranges from 2-3 pups in each gestation [5]. Feeds mainly on bottom- dwelling organisms [12]. In the present study Narcine 
timeli recorded in all landing centre. Narcine prodorsalis is not very common to site and due to few reports and species-specific studies not much information on biology, full dispersal range and threats are available. Hence, $N$. prodorsalis has been entitled as data deficient the International Union of Conservation of Nature
(IUCN) in 2009 [13]. Alifa Bintha Haque and Nazia Hossain report the $1^{\text {st }}$ record of a female $N$. prodorsalis in Bay of Bengal, off the coasts of Bangladesh and prolonging the range of the geographical distribution of the species further west to Andaman Sea, within the Bay of Bengal.

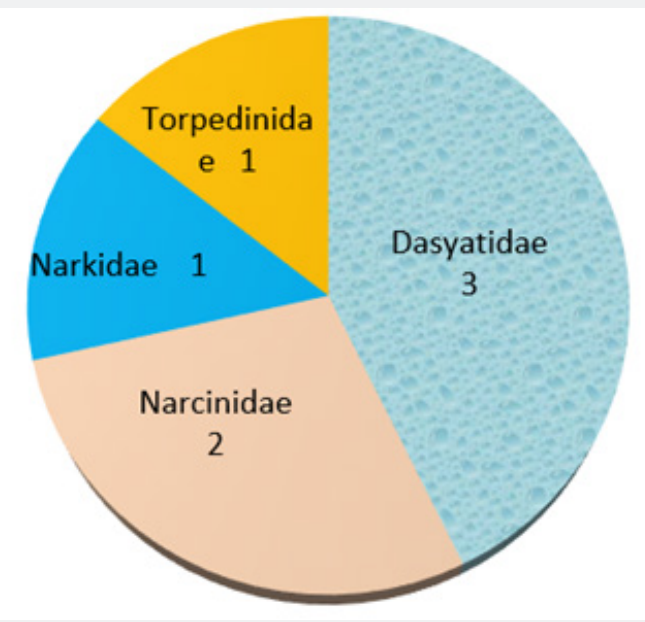

Figure 1: Shows the diversity of rays in family wise.

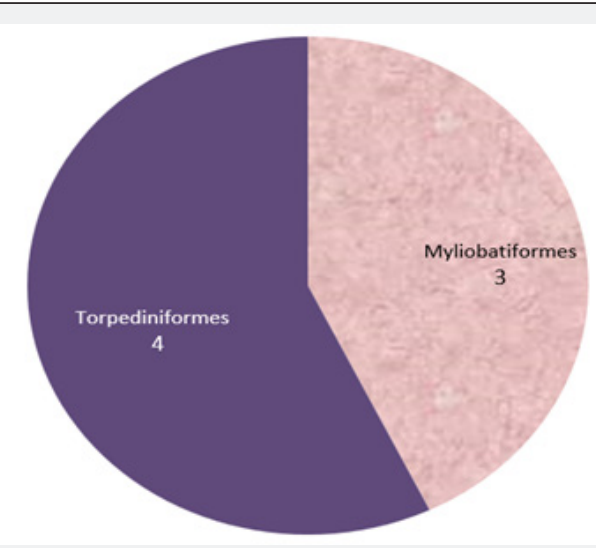

Figure 2: Shows the diversity of rays order wise.

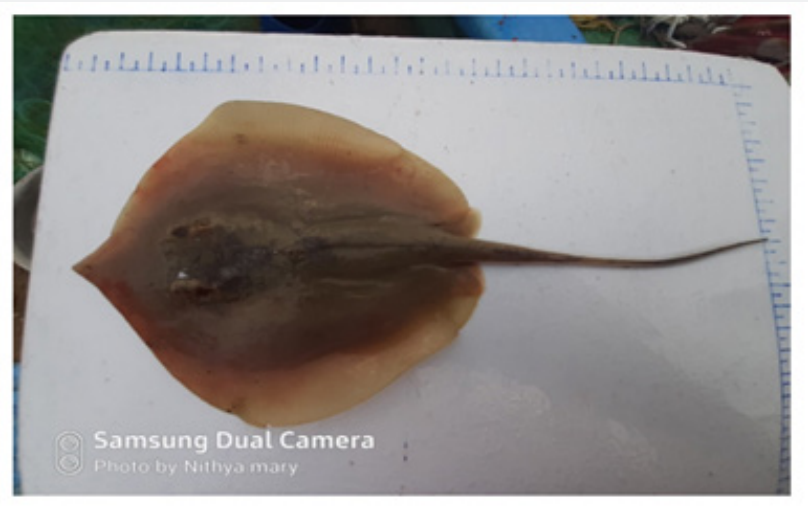

Figure 3: Brevitrygon imbricate 


\section{Oceanography \& Fisheries Open access Journal}

Table 1: Shows the diversity of rays in four landing centres.

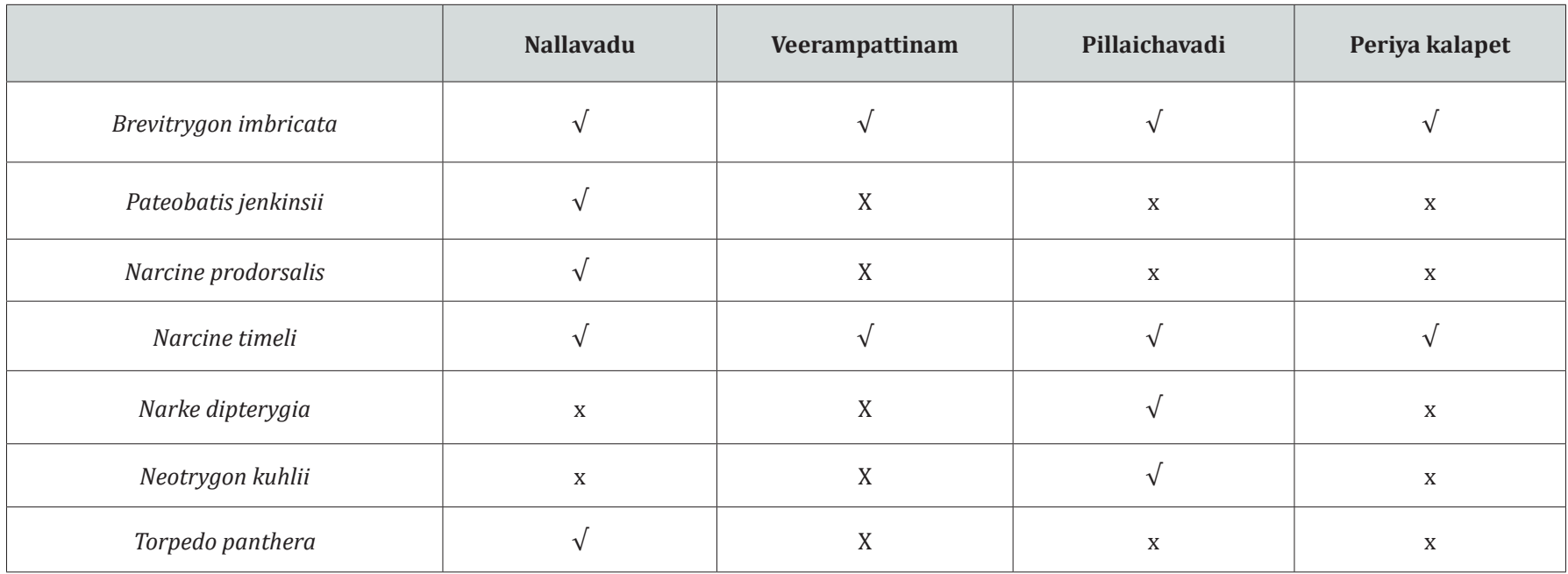

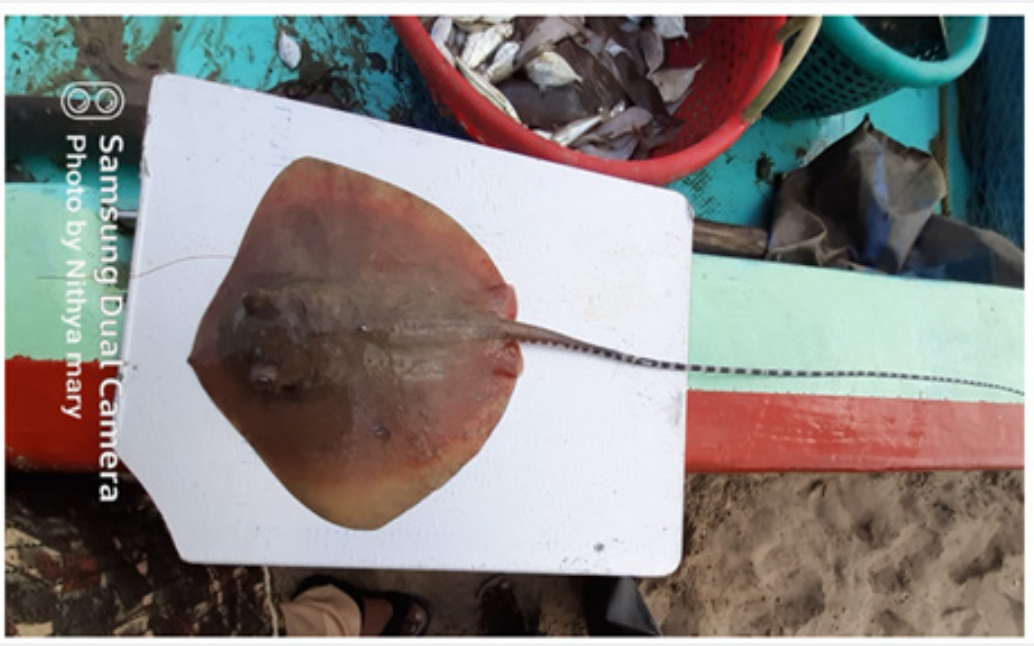

Figure 4: Pateobatis jenkinsii

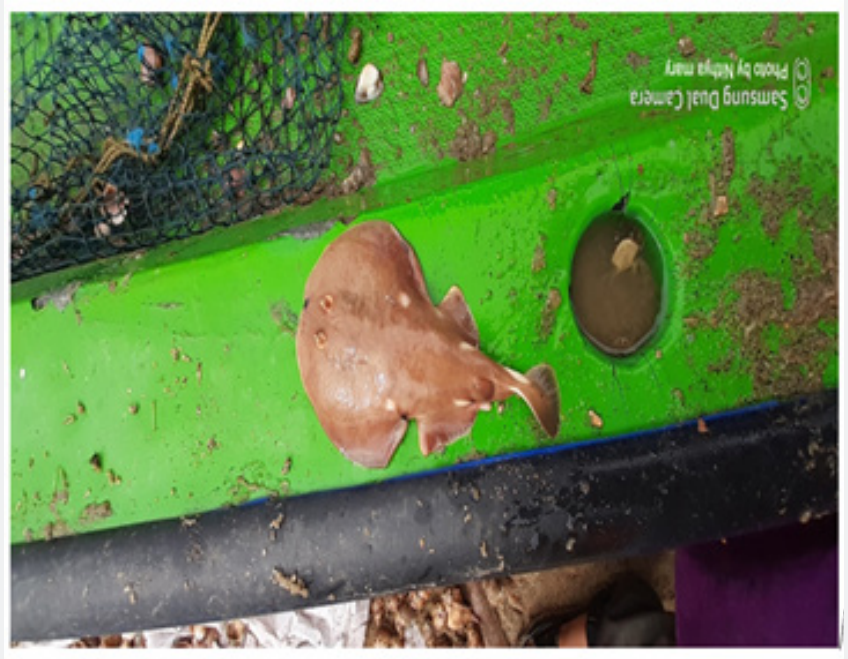

Figure 5: Narke dipterygia 
Figure 6: Neotrygon kuhlii
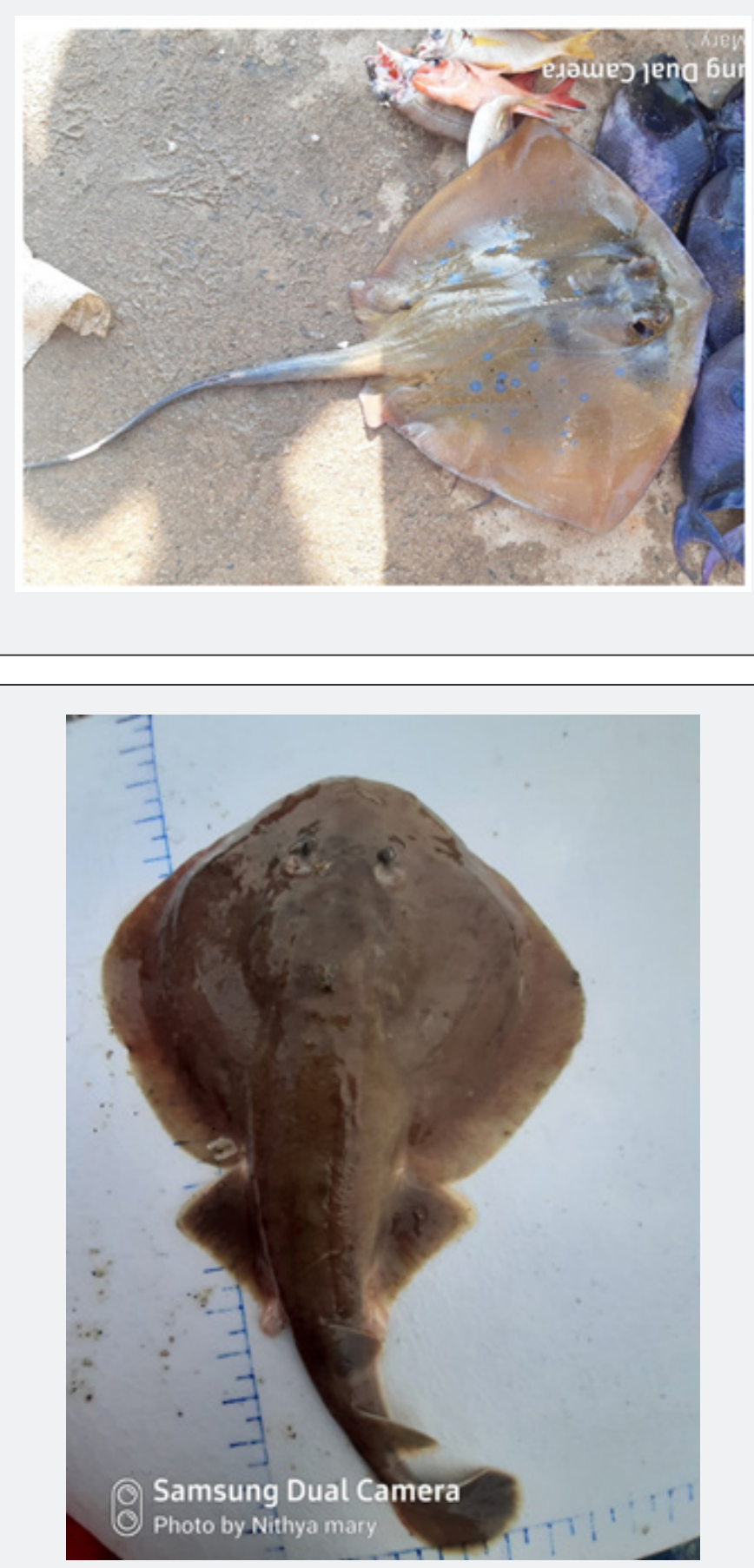

Figure 7: Narcine timeli

In the present study also Narcine Prodorsalis recorded first time in Pondicherry coastal waters. Karuppasamy et al. [14] reported Neotrygon kuhlii from southwest and southeast coast of India. In the present study Neotrygon kuhlii recorded in Coromandel Coast. Eschmeyer et al. [15] reported the Pateobatis jenkinsii in Ganjam coast of Orissa State, India. Similarly, Pateobatis jenkinsii recorded in the present study Nallavadu landing centre. Sujatha et al [16], studied and discussed the taxonomy and length- weight relationship of torpedo electric rays of the genus Torpedo (Pisces: Torpedinidae) off Visakhapatnam coast of India. In the present study Torpedo panthera recorded in Nallavadu landing centre. Ali Momeninejad et al. [17], recorded Narke dipterygia as a first report in Iran water. In the present study Narke dipterygia recorded in Pillaichavadi landing center. So, the present study confirming the diversity and taxonomical identification of rays in Pondicherry coastal waters. 


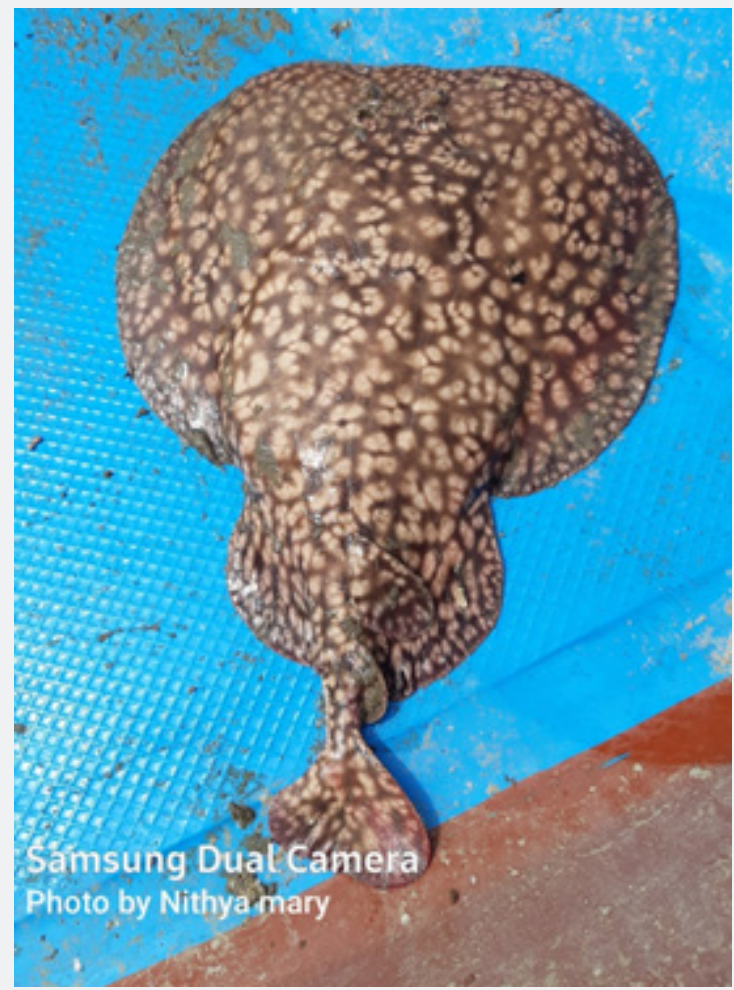

Figure 8: Torpedo panthera

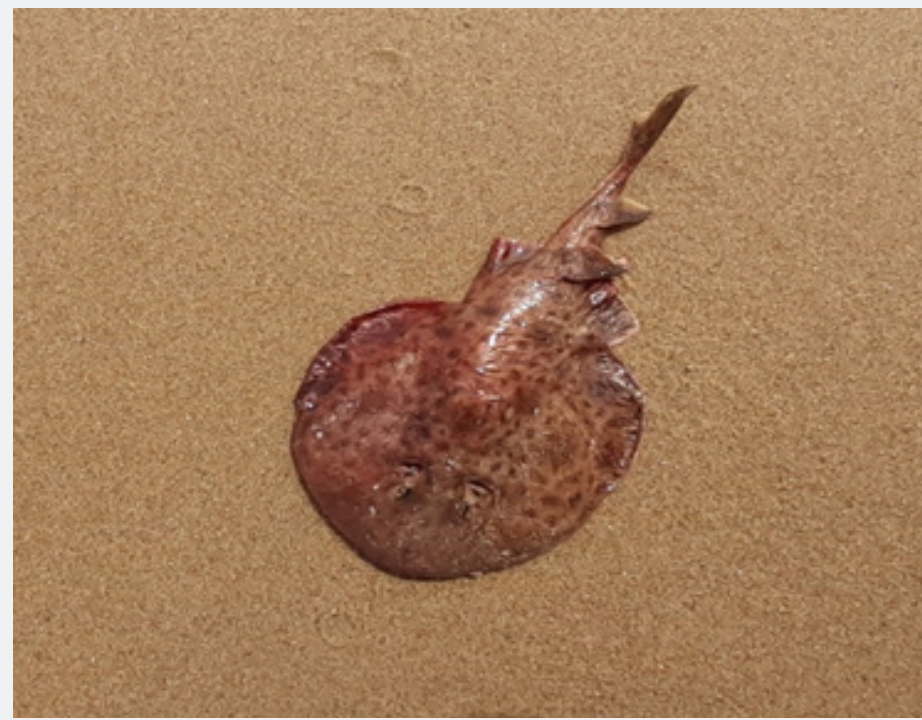

Figure 9: Narcine prodorsalis

\section{References}

1. Bonfil R (2002) Trends and Patterns in World and Asian Elasmobranch Fisheries. In: SL Fowler, TM Reed, FA Dipper (Eds). Elasmobranch biodiversity, conservation, and management: Proceedings of the International Seminar and Workshop in Sabah, July 1997. IUCN SSC Shark Specialist Group. IUCN, Gland, Switzerland and Cambridge, UK.
2. Dulvy NK, Fowler SL, Musick JA, Cavanagh RD, Kyne PM, et al. (2014) Extinction risk and conservation of the world's sharks and rays. eLife 3: e00590.

3. Raje SG, Grace Mathew, KK Joshi, J Rekha Nair, G Mohanraj, et al. (2002) Elasmobranch fisheries of India-An Appraisal. CMFRI Special Publication 71: 76. 
4. Mohanraj G, S Rajapackiam, S Mohan, S Hameed Batcha, S Gomathy (2009) Status of Elasmobranchs Fishery in Chennai, India. Asian Fisheries Science 22(2): 607-615.

5. Last P R, WT White, MR de Carvalho, B Seret, MFW Stehmann, et al. (2016) Rays of the World. CSIRO Publishing, Melbourne.

6. Akhilesh KV, KK Bineesh, A Gopalakrishnan, JK Jena, VS Basheer, et al. (2014) Checklist of Chondrichthyans in Indian waters. Journal of the Marine Biological Association of India 56(1): 109-120.

7. Kizhakudan SJ, KV Akhilesh, S Thomas, KSSM Yousuf, KS Sobhana, et al. (2018) Field Identification of Batoids - A Guide to Indian Species. CMFRI Special Publication No. 132. ICAR-Central Marine Fisheries Research Institute, India.

8. CMFRI (2000-2018) Annual reports from 2000 to 2018, Central Marine Fisheries Research Institute, Cochin, India.

9. Kumar A, GR Deepthi (2006) Trawling and by-catch: Implications on marine ecosystem. Curr Sci India 90: 922-931.

10. Akhilesh KV, U Ganga, NGK Pillai, E Vivekanandan, KK Bineesh, et al. (2011) Deep-sea fishing of chondrichthyan resources and sustainability concerns - a case study from the southwest coast of India. Indian J Geo-mar Sci 40: 347-355.

11. Rainboth WJ (1996) Fishes of the Cambodian Mekong. FAO Species Identification Field Guide for Fishery Purposes. FAO, Rome.
12. Carpenter KE, F Krupp, DA Jones, U Zajonz, (1997) Living marine resources of Kuwait, eastern Saudi Arabia, Bahrain, Qatar, and the United Arab Emirates. FAO species identification field guide for fishery purposes. Rome.

13. Wang Y, C Vidthayanon, B samiengo (2009) Narcine prodorsalis. The IUCN Red List of Threatened Species 2009: e.T161545A5448211.

14. Karuppasamy K, P Jawahar, S David Kingston, VK Venkataramani, V Vidhya (2019) Elasmobranch diversity, conservation and management along Wadge Bank, South India. Indian Journal of Animal Research 54: 367-372.

15. Eschmeyer WN, R Fricke, R van der Laan (2018) Catalog of Fishes: Genera, Species, References.

16. Sujatha K, KVL Shrikanya, NM Krishna (2014) Taxonomy and length weight relationship of torpedo electric rays of the genus Torpedo (Pisces: Torpedinidae) off Visakhapatnam coast of India. Indian Journal of Fisheries 61(4): 24-34.

17. Ali Momeninejad, Yazdan Keivany, Vahid Sultan-mohammadi (2014) First record of the numbray, Narke dipterygia (Bloch \& Schneider, 1801) from Iran (Elasmobranchii: Narkidae). Iranian Journal of Ichthyology 1(4): 298-301.

\section{Your next submission with Juniper Publishers will reach you the below assets}

- Quality Editorial service

- Swift Peer Review

- Reprints availability

- E-prints Service

- Manuscript Podcast for convenient understanding

- Global attainment for your research

- Manuscript accessibility in different formats ( Pdf, E-pub, Full Text, Audio)

- Unceasing customer service

Track the below URL for one-step submission https://juniperpublishers.com/online-submission.php 